\title{
Review Article: Bilingualism and Cognitive and Auditory Processing: A Comprehensive Review
}

\author{
Mahya Sharifinik $^{1}$ (D), Mohsen Ahadi ${ }^{* *}$ (D), Vida Rahimi² ${ }^{2}$ (D) \\ 1. Department of Audiology, Rehabilitation Research Center, Iran University of Medical Sciences, Tehran, Iran. \\ 2. Department of Audiology, School of Rehabilitation, Tehran University of Medical Sciences, Tehran, Iran.
}
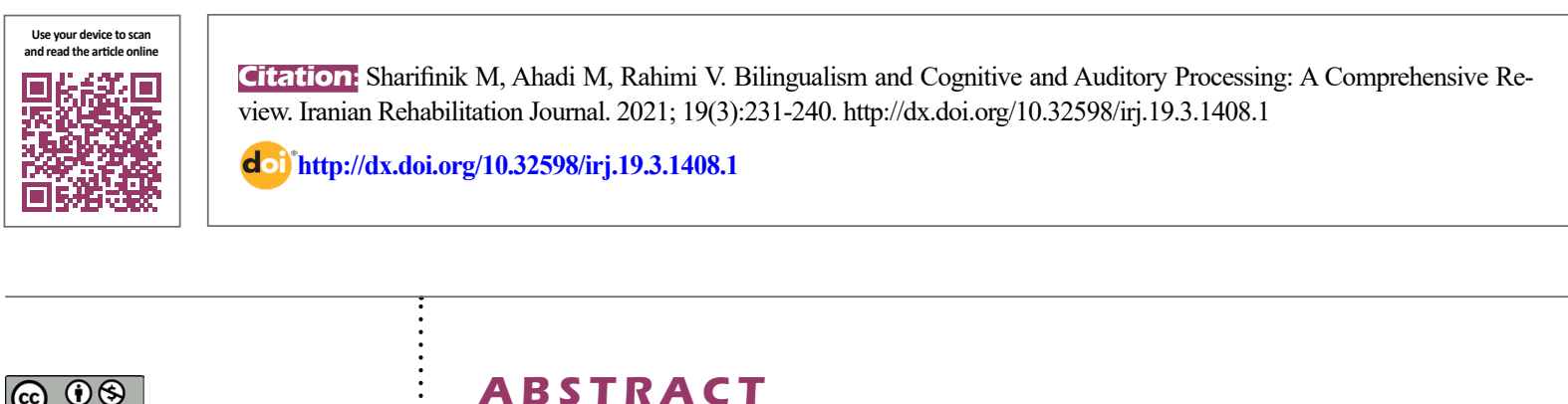

(i) (3)

Article info:

Received: 18 Apr 2021

Accepted: 16 Aug 2021

Available Online: 01 Sep 2021

\section{Keywords:}

Bilingual, Auditory processing, Auditory attention, Memory, Alzheimer's disease

\section{ABSTRACT}

Objectives: Bilingualism and multilingualism are on the rise in many parts of the world. Learning and using other languages, in addition to the expected impact on language domains, can affect non-linguistic fields such as attention, working memory, cognitive control, and auditory processing. The objective of this study was a comprehensive review of the bilingual advantage and disadvantages with emphasis on its effect on the cognitive process and its relationship with auditory processing.

Methods: A total of 133 articles were initially found in this field. According to the inclusion and exclusion criteria of the review, 84 related articles were entered into this study. Then we searched articles published 2005-2020 in Science Direct, Scopus, Google Scholar, and PubMed databases. Keyword and MeSH terms were used in the search process: "bilingualism", "cognitive process", "auditory process", and "auditory attention".

Results: Studies showed that bilingualism not only has advantages in the linguistic domain but also affects the cognitive domain, especially auditory attention, auditory memory capacity, and inhibitory control. Also, it has a protective effect against cognitive decline in aging. Structural changes in the brain in bilinguals support these effects. Most studies reported that enhanced attentional requests of bilingual exchange amplify connectivity among cognitive functions like attentional rein and auditory processing. These effects create more constancy in the auditory evoked response in bilinguals.

Discussion: Learning foreign languages could provoke the autonomic sound processing capability of the auditory organ and make it highly efficient in challenging listening conditions. It also affects other cognitive processes such as auditory memory. However, a comprehensive framework for this relationship is still unknown, and further research is needed, especially to support neurophysiological evidence.

\footnotetext{
* Corresponding Author:

Mohsen Ahadi, PhD.

Address: Department of Audiology, Rehabilitation Research Center, Iran University of Medical Sciences, Tehran, Iran.

Tel: +98 (21) 22222059

E-mail: mohsenahadi@yahoo.com
} 


\section{Highlights}

- Learning a foreign language could provoke the autonomic sound processing capability of the auditory organ and make it highly efficient in challenging listening conditions.

- Bilingualism affects the cognitive domain, especially auditory attention, auditory memory capacity, and inhibitory control.

- Bilingualism has a protective effect against cognitive decline in aging (Alzheimer's disease).

\section{Plain Language Summary}

Bilingualism and multilingualism are on the rise in many parts of the world. In this review, we summarized the effect of bilingualism on central auditory and cognitive processes. Bilingualism is essential not only in linguistics but also in other aspects of central auditory processing such as auditory memory, auditory processing in complex listening environments, and auditory attention. In addition, learning a second language can delay cognitive impairment in old age, such as Alzheimer's disease. Structural changes in the brain in bilinguals support these effects. However, a comprehensive framework for this relationship is still unknown, and further research is needed, especially to support neurophysiological evidence.

\section{Introduction}

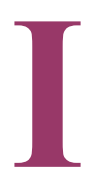

$\mathrm{n}$ many countries, individuals speak at least two languages. In some parts of the world, like in the Netherlands, more than two languages are educated at school [1]. Migration, the expansion of the Internet, and an increment in traveling for jobs or globe-trotting are among the reasons for the development of multilingualism, especially bilingualism [2]. Studies show that bilingualism not only has a positive effect on the linguistic aspect but can also affect other non-linguistic areas like the working memory [3], cognitive control [4], attention [5], auditory processing [6], and prevention of some cognitive disease like dementia [7].

In bilinguals, the use of two languages in conversation improves inhibitory performances that subsequently reinforce attentional control. Most research reports that increased attention request in bilingual exchange leads to a strengthening of cognitive functions such as attention control and auditory processing. These findings are supported by electrophysiological assessments of the auditory system in these individuals $[7,8]$. One of the other skills in the cognitive domain is memory. Bilingualism could positively affect auditory memory. The studies showed the protecting efficacy of second language learning against a decrease in cognitive abilities like dementia and diseases like Alzheimer. Some research studies reported a positive effect, while further studies showed that bilingualism had no advantages over monolingual.
Moreover, some evidence shows that bilingualism can delay the beginning of dementia by 4 to 5.5 years [8-10].

According to studies, the auditory organ is the best example for investigating top-down mechanisms like attention and inhibitory control on sensory processing. In several studies, speech elicited auditory brain stem response (speech ABR) showed an increased subcortical display of the fundamental frequency (f0) of the speech sound, in addition to better sustained selective attention in bilingual people [11-13]. Attention capability is associated with the f0 strength, which is the fundamental frequency of sound in speech ABR until the stimulus is delivered in a multi-talker babble noise rather than in silence [6].

This review intends to establish a comprehensive analysis of the research in the effect of second language learning on cognitive control and auditory processing, which auditory tests could assess. We also focused on the cognitive advantages, such as improved attention and cognitive control skills by auditory electrophysiological tests and possible disadvantages. In addition, we summarized the implication of bilingualism on the prevention of diseases such as Alzheimer and dementia [7, 14].

\section{Auditory attention in bilingualism}

Bilinguals, compared to monolinguals, can better scout contradictory sensory information and adjust a pertaining stimulus via an inhibitory control that is firmly paired with focusing and maintaining attention $[6,15$, 
16]. Studies show that attention capability is related to the energy of the $\mathrm{f0}$ in speech ABR when the stimulus is transferred in multi-talker babble noise background. However, there was no correlation between attention abilities and strength of the f0 when there was no background noise (in quiet).

Sustained selective attention improved the subcortical display of the fundamental frequency (f0) of the speech sound. Association between persistent selective attention and electrophysiology results were according to the outcome on the auditory attention duty and the neural coding of the $\mathrm{fO}$ in quiet and babble noise. Investigation showed that $\mathrm{f0}$ amplitude in quiet does not affect auditory attention in a quiet environment, while the neural coding of the $\mathrm{f0}$ in multi-talker babble is directly related to sustained selective auditory attention [6]. Because of reinforcement of inhibitory skills by using two languages during ordinary conversations, attentional control abilities improve. This advantage can impress sensorial coding via top-down signaling, so the higher level of attentional control in bilingual people leads to a powerful effect on auditory processing and authorizing the hearing system inpatient with two languages to more efficaciously receive behaviorally-relevant traits of the inbound sounds [7].

Based on studies, an increase in the interplay among cognitive and sensory processing in bilingualism shows greater stability in evoked response recorded from scalp to sound for bilinguals compared to monolinguals. Comparing attentional capacities by the stabilities of auditory cortical and brainstem potentials to a speech syllable evoked under inactive listening status in bilingual and monolingual indicate that a correlation exists between the stability of the auditory brainstem response and attentional control capabilities $[6,7,17,18]$. This relationship could have two reasons. First, the efferent routes connect the executive system to the subcortical auditory system, which is intensified by speaking two languages [19, 20]. Second, via a lifetime of simultaneously involving both attentional control and auditory processing, these two systems become synergistically connected. Thus, topdown pathways are involved even under passive listening, resulting in a unique relation across attentional control and subcortical auditory processing in bilinguals [7].

Highly proficient bilinguals have higher attentional control, paired with more stability in the subcortical evoked response. This relationship between proficiency in both languages and better attentional control proposes that language experience affects the automated sensory encoding of auditory signals by improving top-down processing currents that lead to refinement of bottomup signal conduction $[7,11,21]$. The effect of auditory brainstem function by bilingualism can be measured with various instruments, one of which is frequency Following Response (FFR) which indicates that learning other languages can be associated with plasticity in the auditory brainstem. FFR shows the synchronized activities of axonal and dendritic potentials produced with the sum of neurons in the lateral lemniscus and inferior colliculus of the brain stem and is suitable for assessing how subcortical areas encode speech-specific pitch contours. It shows alterations in auditory brainstem encoding of f0 (pitch) patterns which is a subcortical response likely emanated from the rostral brainstem encoding the f0 (a physiological correlate of perceived pitch) of the stimuli with vast fealty [22].

Some studies show that although bilingualism can improve general non-linguistic aspects of cognition, it can negatively affect language competence. The superiorities of bilingualism are especially obvious in tasks that involve cognitive inflection and the control of attention; it seems to be better at specifically pay attention, suppressing irrelative data, and shifting among the alternative solution to a problem [23-25].

One of the features of hearing processing is speech perception in noise. Research indicates that people as monolingual and bilingual perform a similar function in word comprehension in noise, but bilinguals perform better when comprehension of speech in noise is examined in sentence context. Tone-in-noise detection needs no linguistic notice, while sentence-in-noise discernment depends on vocabulary, syntax, and context. Thus, depending on the situation, bilinguals can have advantages and disadvantages during listening to background noise $[25,26]$.

Late bilinguals also have an advantage of auditory attention, and it is not specific to learning a second language in early childhood. Bilingual people who learn a second language early or late both enjoy the benefits of bilingualism, but in two various manners: the early group through attention exchange and the late group through selective attention and inhibition. It appears that learning a foreign language too soon at childhood raise switching processes, whereas the later learning of a second language after the stabilization of the native language may need powerful inhibition of the native predominant language, thus, have a significant effect on inhibitory control [24]. 


\section{Auditory memory in bilingualism}

Auditory memory has an essential role in language learning. To learn a language, correct encoding and retrieval of information from memory are needed, so memory and language are closely related [27]. Auditory memory is the ability to receive auditory stimuli, process the stimuli, and then store them. This kind of memory is essential for linguistic skills growth (such as learning and remembering words and also the ability to perceive and use grammar) and the learning process [28]. Some research shows that auditory capacity is higher in bilinguals compared with monolinguals [29, 30]. Soleymani et al. studied short-term auditory memory function through dichotic auditory-verbal memory tests in monolinguals and precocious bilinguals (a person who learns the second language early in childhood). The study results exhibit a significant increment in the score of the dichotic auditory-verbal memory test in the bilinguals [31]. The auditory memory is positively influenced by bilingualism. Goldstein et al. also showed that the prefrontal cortex, which has an essential function in the auditory memory in bilinguals, is more active than monolinguals $[32,33]$.

Recent studies show that cognitive advantages in bilinguals are beyond inhibition. They have advantageous for function on working memory exercise that requires a higher level of executive control. This finding supports the assumption that experiencing two language handling impacts the central executive control system that arranged processing over a broad limit of functional requests [34]. There was a positive relationship between bilingual performance and working memory, so working memory tasks and advantages to executive control are influenced by bilingual efficiency [35]. Elma Blom reported that Turkish-Dutch bilingual children compared with Dutch monolinguals, have cognitive benefits in visuospatial and verbal working memory exercise [36]. The results of this study, in line with other studies, showed the benefit of bilingualism regardless of inhibition $[37,38]$. Bilingual cognitive benefits develop irrespective of socioeconomic status background, and learning two languages can be a critical source of richness for socioeconomically deprived children [39-41].

\section{Auditory processing in bilingualism}

Learning a second language may evoke the sound processing capabilities of the auditory system and make it highly efficient in regular and challenging listening conditions. The individuals who learn the second language would develop plasticity in cortical regions of the brain that are responsible for processing language and executive control. It benefits from better inhibitory control, allowing bilinguals to discriminate the characteristics of the desired stimulus better, even if the latter is presented in conjunction with an unrelated and disturbing signal, such as noise [6].

In this regard, studies were conducted in both behavioral and electrophysiological fields. Amanda Dal Piva Gresele (2013) compared the binaural hearing capability in people who speak only Brazilian (control group) and people who speak Brazilian and German simultaneously (the study group A) or consecutive two languages of Brazilian and Italian (SGI) with dichotic digit test (DDT), and staggered spondee word (SSW) test. The result of DDT showed the discrepancy between two ears in all scores between study group A to the control group. Comparison of the study group A and I show no discrepancy between them. The SSW outcomes represent that the two study groups have better scores in both ears, and it was meaningful compared to the control group. The results show the asymmetry in the activity of brain hemispheres. Also, it shows dominancy in the left temporal lobe. Results show that study group I has significantly better scores than study group A. It could be concluded that bilingualism has a beneficial effect on the prediction of dichotic listening, shown in DDT results. The outcome of SSW is significantly better for consecutive Brazilian Portuguese-Italian than simultaneous Brazilian Portuguese-German [42].

Isabell Wartenburger et al. (2003) performed syntactic and semantic exercises in both people who learn the second language in childhood and late adulthood. The results showed that in syntax tasks, the activity of the Broca's area, inferior frontal gyrus, and the right hemisphere increased in people who learned the second language in adulthood [43].

In the electrophysiological field, evaluations were performed using speech-ABR, an objective experiment to observe how subcortical structures of the auditory pathway encode speech sounds. The stimulus used in speechABR is usually /da/. The chosen phonemes (e.g., /da/) are found in most languages, and no group has a greater advantage over the other in processing that sound [13, 44]. Speech-ABR studies in bilinguals showed that the neural onset (wave V), the consonant transition (wave $\mathrm{C})$, and the harmonic region (D, F) responses showed longer latencies in the monolingual group compared to their bilingual peers; increased peak latencies could be an indicator of a disruption of the encoding process. This event would suggest that the wave's latency could be 
considered as a neural biomarker distinguishing between the two groups of bilingual and monolingual. Moreover, when speech stimuli were present in noise, the processing of the transition between consonant $/ \mathrm{d} /$ to $/ \mathrm{a} /$ required a longer time in monolinguals than bilinguals. Click ABR shows no significant difference between monolinguals and bilinguals [12, 45, 46]. It suggests that bilinguals exhibit more efficient auditory processing capacities in quiet and noisy conditions than monolinguals (Figure 1) [7, 12]. Krizman et al. (2012) performed speech-ABR on bilinguals and monolinguals. They found a relationship between enriched linguistic environments such as a bilingual environment in contrast to a monolingual environment and the neural response of the auditory system. Although cortical and subcortical auditory evoked responses were present in monolingual and bilingual groups, the two evoked potentials in bilinguals were more pronounced and had a larger amplitude [6].

There was a significant change in the speech-ABR morphology of the waves when comparing the noisy listening condition to the quiet condition; waves with a smaller amplitude and longer latency were observed in the noisy condition [12]. FFR is evoked by the harmonic part of the vowel, which refers to the latter portion of the speech-ABR. It showed that the f0 was encoded more robustly in bilingual, whether in silent or noisy conditions. In the noise, since consonants are more affected than vowels, the FFR is more robust than the onset and the transition response $[13,47]$.

According to studies, the lexical feature is one aspect of central auditory processing affected by bilingualism. There are some disadvantages of bilingualism in the lexical domain of competence and access; there is the slower recovery of vocabularies in bilinguals than in monolinguals [45, 48]. Another disadvantage in bilinguals is a delay in language acquisition because phonological, lexical, and grammatical systems of two languages interfere, and there is a decrease in vocabulary storage in both languages [49]. Krizman et al. studied hearing in noise skills in monolinguals and bilinguals. The results showed that bilinguals are better in tone-in-noise tests, but they were worse than monolinguals in the sentenceto-noise test, so necessarily, bilinguals do not perform better than monolinguals in all noisy situations [25].

\section{Structural change in bilingualism}

Imaging studies show that bilingualism creates structural changes in addition to functional changes. Early acquisition of a second language and higher skill in bilingualism are associated with more volume of gray matter in the left inferior parietal cortex. Degeneration of gray area of left inferior parietal cortex relates to switching between two languages unintentionally; it suggests its significant role in manipulating the balance between two languages. In addition, there are changes in white matter volume in people who learn second languages early in childhood or late in adulthood [50-52]. Alejandro Pérez Fernández (2014) showed two sub-networks structures linked more by white matter routes in bilingual people than those who speak only one language: these areas consist of left frontal and parietal/temporal regions [53]. The latter contains left occipital and parietal/temporal parts and the right superior frontal gyrus. Their techniques were diffusion-weighted MRI tractography; they used network-based statistic as a manner. This increased connectivity is associated with language processing and monitoring so that bilingualism could improve sub-networks of the language area.

Histological analysis shows a morphological change in subcortical structures, especially in the thalamus, putamen, left globus pallidus, and right caudate nucleus in bilingual people. A topographical rendering indicates that bilinguals have a complex phonological system to improve a subcortical network of the brain, contributing to monitoring articulation processing. Nandini C. Singh (2017) investigated the white-matter microstructure of the cerebral area. She used the diffusion tensor imaging (DTI) method; this method is used to mapping the whitematter microstructure of the cerebral area. DTI consists of two measures that are Mean Diffusivity (MD) and Fractional Anisotropy (FA) MD. The results showed that the shape of white matter alters in bilingual people. Nonetheless, the alteration amount of the neural structure at the subcortical region in bilingual people is not apparent. There is a need for more investigation [52, 53].

\section{Bilingualism effect on Alzheimer's disease}

Learning two languages seems to have a preservative effect against age-related cognitive deterioration. In the research of Viorica Marian et al., about 250 bilingual and monolingual participants with Alzheimer's disease were assessed. The participants with two languages reporting early complications of the disease 5.1 years later than the monolingual people. Besides, other studies showed that old bilinguals have better memory and executive control than old monolinguals. Cognitive decline usually comes along with old age, but bilingualism can protect against the decrement, like Alzheimer's disease [14, 46]. Persons with greater cognitive reserve perform better than those with a smaller degree of cognitive storage after the same amount of brain pathology [48]. This status is called the 

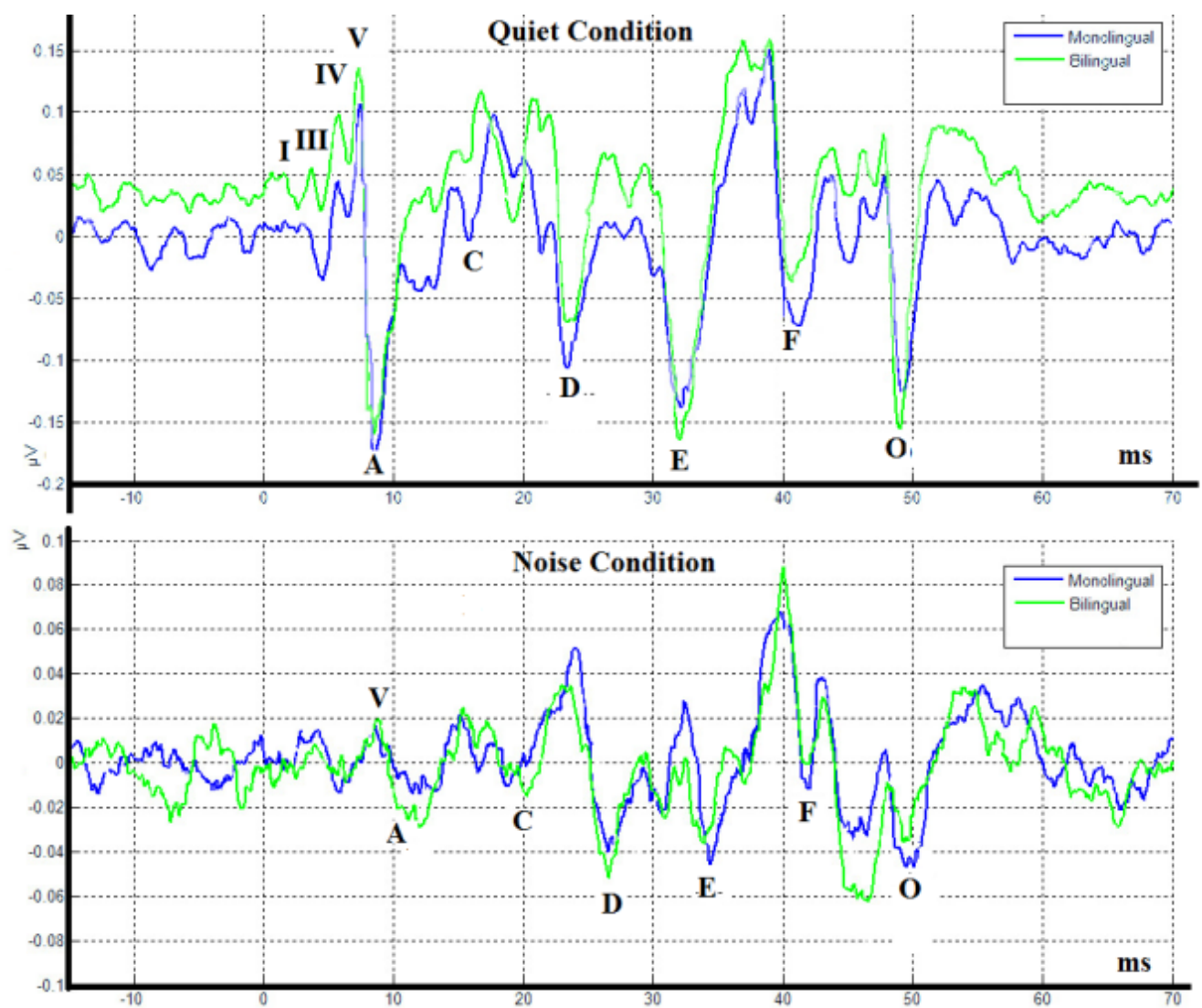

Figure 1. Speech elicited auditory brain stem response

Пranian Rehabilitation \ournal

obtained from the two groups: Monolinguals (Blue) and Bilinguals, (Green) Recorded in Quiet and in Noise [25]

"cognitive reserve hypothesis" [49, 54]. The cognitive reserve hypothesis concerns diversity in brain pathology due to the discrepancy in cognitive processing through variations in an individual's lifetime exposures, intellectual and contextual activities [8]. Thus, bilingualism might be taking part in cognitive reserve and contributes to preservation against or a delay at the beginning of major neurocognitive disorders, such as dementia. Some research shows a relation between these cognitive reserve-enhancing agents and decreased risk of dementia $[55,56]$. In the first phase of dementia, the neurons and their connections that are involved in memory in the hippocampal [57] and entorhinal cortex [58] region are damaged [57]. In the second phase of dementia, regions in the cerebral cortex that affect language acquisition, logic, and social behavior are affected [55]. Some studies show that several parts of the brain might be contributed to the cognitive reserve, which heightens the impact of bilingualism $[59,60]$. Therefore, bilingualism can assist a person versus cognitive deterioration in geriatric time because of more cognitive reserve and can postpone the beginning of dementia.

\section{Conclusion}

This review article was conducted on bilingualism to show if there are advantages to cognitive control, auditory processing, brain structural changes, and preventive effect against cognitive decrement in bilinguals. First, the study focused on the function of bilinguals on cognitive control tasks. Second, we investigated the auditory processing in bilinguals and the structural variations between bilinguals and monolinguals; at the end, we show the preservation impact on cognitive decrement in bilinguals.

This review indicates that the most original articles show advantages of bilingualism in cognitive ability; but, few studies have shown different results, indicating the harmful effects of bilingualism. One explanation for this finding is related to using different methodologies like the sample sizes and the use of various experiments. Bilinguals have better working memory; bilinguals can better attend to related data and deny unrelated ones. They exhibit more efficient auditory processing capacities in quiet and noisy conditions compared to monolinguals. The individual who experiences the second language would have plasticity in cortical regions of 
the brain that are responsible for processing language. In bilingualism, a higher gray mass in the left inferior parietal cortex may significantly handle the equivalency between two languages. White matter volume changes in bilinguals too.

It is interesting that in bilinguals, dementia could start some years later than in monolinguals. Given the increasing number of the elderly and the prevalence of Alzheimer and dementia, finding a factor that can prevent the occurrence of these diseases will be very useful and interesting. Bilingualism could have a preventive effect against cognitive deterioration. These protective effects are in people trained in a foreign language early in childhood or late in adulthood. Regarding the age of learning a foreign language, no evidence has been found so far on the adverse effects of learning two languages simultaneously. An ideal way is to learn both languages at the same time.

In conclusion, bilingual advantages go beyond the linguistic domain and involve a cognitive domain like attention, especially auditory attention, inhibitory control, and memory capacity. Also, it is associated with anatomical, operational, and lateralization brain changes. It has a preventive effect on cognitive decrement by aging. Few studies report some disadvantages in bilingualism in the lexical domain, but there is insufficient evidence in this regard. We still have little knowledge about bilingualism and its effects on the brain, but over time the path ahead becomes more apparent.

Finally, in this review study, some points must be considered in the design of further studies on the bilingualism benefit and disadvantages in cognitive ability and structural changes:

1- The description of the participating bilinguals should be precise and detailed.

2- Perform standard objective tools according to the goal of the study recommended.

3- The use of larger sample sizes is recommended in studies.

4- Future studies should examine whether the benefits mentioned in cognitive characteristics belong only to professional bilinguals such as translators, or we can see skills improvements in other bilinguals as well.

5- Longitudinal studies are recommended because learning a second language is complex and dynamic.
6- Further imaging studies are recommended to show their association and neurophysiological support.

\section{Ethical Considerations}

Compliance with ethical guidelines

There were no ethical considerations to be considered in this research.

\section{Funding}

This research did not receive any grant from funding agencies in the public, commercial, or non-profit sectors.

\section{Authors' contributions}

All authors equally contributed to designing, running, and writing all parts of the research.

\section{Conflict of interest}

The authors declared no conflict of interest.

\section{References}

[1] Ansaldo AI, Marcotte K, Scherer L, Raboyeau G. Language therapy and bilingual aphasia: Clinical implications of psycholinguistic and neuroimaging research. Journal of Neurolinguistics. 2008; 21(6):539-57. [DOI:10.1016/j.jneuroling.2008.02.001]

[2] Milambiling J. Bringing one language to another: Multilingualism as a resource in the language classroom. English Teaching Forum. 2011; 49(1):18-35. https:/ / eric.ed.gov/?id=EJ936091

[3] Blom E, Küntay AC, Messer M, Verhagen J, Leseman P. The benefits of being bilingual: Working memory in bilingual Turkish-Dutch children. Journal of Experimental Child Psychology. 2014; 128:105-19. [DOI:10.1016/j.jecp.2014.06.007] [PMID]

[4] Blumenfeld HK, Marian V. Cognitive control in bilinguals: Advantages in stimulus-stimulus inhibition. Bilingualism: Language and Cognition. 2014; 17(3):610-29. [DOI:10.1017/ S1366728913000564] [PMID] [PMCID]

[5] Friesen DC, LatmanV, Calvo A, Bialystok E. Attention during visual search: The benefit of bilingualism. The International Journal of Bilingualism. 2015; 19(6):693-702. [DOI:10.1177/1367006914534331] [PMID] [PMCID]

[6] Krizman J, Marian V, Shook A, Skoe E, Kraus N. Subcortical encoding of sound is enhanced in bilinguals and relates to executive function advantages. Proceedings of the National Academy of Sciences of the United States of America. 2012 109(20):7877-81. [DOI:10.1073/pnas.1201575109] [PMID] [PMCID] 
[7] Schroeder SR, Marian V. A Bilingual Advantage for Episodic Memory in Older Adults. Journal of Cognitive Psychology. 2012; 24(5):591-601. [DOI:10.1080/20445911.2012.669367] [PMID] [PMCID]

[8] Barulli D, Stern Y. Effciency, capacity, compensation, maintenance, plasticity: Emerging concepts in cognitive reserve. Trends in Cognitive Sciences. 2013; 17(10):502-9. [DOI:10.1016/j.tics.2013.08.012] [PMID] [PMCID]

[9] Chodosh J, Reuben DB, Albert MS, Seeman TE. Predicting cognitive impairment in high-functioning community-dwelling older persons: MacArthur Studies of Successful Aging Journal of the American Geriatrics Society. 2002; 50(6):1051-60. [DOI:10.1046/j.1532-5415.2002.50260.x] [PMID]

[10] Bialystok E, Craik FIM, Freedman M. Bilingualism as a protection against the onset of symptoms of dementia. Neuropsychologia. 2007; 45(2):459-64. [DOI:10.1016/j.neuropsychologia.2006.10.009] [PMID]

[11] Centanni TM, Booker AB, Sloan AM, Chen F, Maher BJ Carraway RS, et al. Knockdown of the dyslexia associated gene kiaa0319 impairs temporal responses to speech stimuli in rat primary auditory cortex. Cerebral Cortex. 2014; 24(7):175366. [DOI:10.1093/cercor/bht028] [PMID] [PMCID]

[12] Koravand A, Thompson J, Chénier G, Kordjazi N. The effects of bilingualism on speech evoked brainstem responses recorded in quiet and in noise. Canadian Acoustics. 2019; 47(2):23-30. https://jcaa.caa-aca.ca/index.php/jcaa/article/view/3290

[13] Russo N, Nicol T, Musacchia G, Kraus N. Brainstem responses to speech syllables. Clinical Neurophysiology. 2004; 115(9):2021-30. [DOI:10.1016/j.clinph.2004.04.003] [PMID] [PMCID]

[14] Thierry G, Wu YJ. Brain potentials reveal unconscious translation during foreign-language comprehension. Proceedings of the National Academy of Sciences of the United States of America. 2007; 104(30):12530-5. [DOI:10.1073/ pnas.0609927104] [PMID] [PMCID]

[15] Reck SG, Hund AM. Sustained attention and age predict inhibitory control during early childhood. Journal of Experimental Child Psychology. 2011; 108(3):504-12. [DOI:10.1016/j. jecp.2010.07.010] [PMID]

[16] Bialystok E. Reshaping the mind: The benefits of bilingualism. Canadian Journal of Experimental Psychology. 2011; 65(4):229-35. [DOI:10.1037/a0025406] [PMID] [PMCID]

[17] Coch D, Sanders LD, Neville HJ. An event-related potential study of selective auditory attention in children and adults. Journal of Cognitive Neuroscience. 2005; 17(4):605-22. [DOI:10.1162/0898929053467631] [PMID]

[18] Hairston WD, Letowski TR, McDowell K. Task-related suppression of the brainstem frequency following response. PLoS One. 2013; 8(2):e55215. [DOI:10.1371/journal.pone.0055215] [PMID] [PMCID]

[19] Raizada RDS, Poldrack RA. Challenge-driven attention: interacting frontal and brainstem systems. Frontiers in Human Neuroscience. 2008; 1:3. [DOI:10.3389/neuro.09.003.2007] [PMID] [PMCID]

[20] Weissman DH, Roberts KC, Visscher KM, Woldorff MG. The neural bases of momentary lapses in attention. Nature Neuroscience. 2006; 9(7):971-8. [DOI:10.1038/nn1727] [PMID]
[21] Hornickel J, Kraus N. Unstable representation of sound Abiological marker of dyslexia. The Journal of Neuroscience 2013; 33(8):3500-4. [DOI:10.1523/JNEUROSCI.4205-12.2013] [PMID] [PMCID]

[22] Song JH, Skoe E, Wong PCM, Kraus N. Plasticity in the adult human auditory brainstem following short term. Journal of Cognitive Neuroscience. 2008; 20(10):1892-902. [DOI:10.1162/ jocn.2008.20131] [PMID] [PMCID]

[23] Bialystok E. Bilingualism: The good, the bad, and the indifferent. Bilingualism: Language and Cognition. 2009; 12(1):3-11. [DOI:10.1017/S1366728908003477]

[24] Bialystok E, Craik FIM, Klein R, Viswanathan M. Bilingualism, aging, and cognitive control: Evidence from the Simon task. Psychology and Aging. 2004; 19(2):290-303. [DOI:10.1037/0882-7974.19.2.290] [PMID]

[25] Kraus N, White-Schwoch T. The bilingualism paradox The Hearing Journal. 2017; 70(1):40-2 [DOI:10.1097/01. HJ.0000511727.48959.2d]

[26] Sorace A. 2011. Cognitive advantages in bilingualism: Is there a bilingual paradox? In: Valore $\mathrm{P}$, editor. Multilingualism. Language, Power, and Knowledge. Pisa: Edistudio; 2011. p. 335-8. https://books.google.com/ books?id=DgarngEACAAJ\&dq

[27] Francis WS, Gutiérrez M. Bilingual recognition memory: stronger performance but weaker levels-of processing effects in the less fluent language. Memory \& Cognition. 2012; 40(3):496-503. [DOI:10.3758/s13421-011-0163-3] [PMID]

[28] Cusimano A. Learning disabilities: There is a cure-a guide for parents, educators and physicians. $1^{\text {st }}$ ed. Lansdale, PA Achieve Publications; 2001. https://books.google.com/ books?id=Il510IyaZlYC\&dq

[29] Krizman J, Marian V, Shook A, Skoe E, Kraus N. Subcortical encoding of sound is enhanced in bilinguals and relates to executive function advantages. Proceedings of the National Academy of Sciences of the United States of America. 2012; 109(20):7877-81. [DOI:10.1073/pnas.1201575109] [PMID] [PMCID]

[30] Jalilvand Karimi L, Motlaghzadeh L, Mohammadkhani G, Akbarzadeh Baghban A. The comparison of auditory capacity between bilinguals and monolinguals by consonant-vowel dichotic test (Persian)]. Scientific Journal of Rehabilitation Medicine. 2013; 2(3):19-30. http:// medrehab.sbmu.ac.ir/article_1100113_en.html

[31] Soleymani M Jarollahi F, Hosseini F, Rahmani E. The effects of bilingualism on auditory memory using Persian version of dichotic auditory-verbal memory test. Auditory and Vestibular Research Journal. 2015; 24(3):19-24. https://avr.tums ac.ir/index.php/avr/article/view/12

[32] Smith EE, Jonides J. Storage and executive processes in the frontal lobes. Science. 1999; 283(5408):1657-61. [DOI:10.1126/ science.283.5408.1657] [PMID]

[33] Goldstein JM, Jerram M, Poldrack R, Anagnoson R, Breiter HC, Makris N, et al. Sex differences in prefrontal cortical brain activity during fMRI of auditory verbal working memory. Neuropsychology. 2005; 19(4):509-19. [DOI:10.1037/08944105.19.4.509] [PMID]

[34] Engle RW, Kane MJ. Executive attention, working memory capacity, and a two factor theory of cognitive control. In Strong R, editor. The Psychology of Learning and Motivation. New York: Elsevier; 2004. p. 145-99. [DOI:10.1016/S00797421(03)44005-X 
[35] Gathercole VCM, Thomas EM, Kennedy I, Prys C, Young N, Viñas Guasch N, et al. Does language dominance affect cognitive performance in bilinguals? Lifespan evidence from preschoolers through older adults on card sorting, Simon, and metalinguistic tasks. Frontiers in Psychology. 2014; 5:11. [DOI:10.3389/fpsyg.2014.00011] [PMID] [PMCID]

[36] Morales J, Calvo A, Bialystok E. Working memory development in monolingual and bilingual children. Journal of Experimental Child Psychology. 2013; 114(2):187-202. [DOI:10.1016/j.jecp.2012.09.002] [PMID] [PMCID]

[37] Blom E, Küntay AC, Messer M, Verhagen J, Leseman P. The benefits of being bilingual: Working memory in bilingual Turkish-Dutch children. Journal of Experimental Child Psychology. 2014; 128:105-19. [DOI:10.1016/j.jecp.2014.06.007] [PMID]

[38] Bialystok E. Global-local and trail-making tasks by monolingual and bilingual children: Beyond inhibition. Developmental Psychology. 2010; 46(1):93-105. [DOI:10.1037/ a0015466] [PMID] [PMCID]

[39] Calvo A, Bialystok E. Independent effects of bilingualism and socioeconomic status on language ability and executive functioning. Cognition. 2014; 130(3):278-88. [DOI:10.1016/j. cognition.2013.11.015] [PMID] [PMCID]

[40] Carlson SM, Meltzoff AN. Bilingual experience and executive functioning in young children. Developmental Science. 2008; 11(2):282-98. [DOI:10.1111/j.1467-7687.2008.00675.x] [PMID] [PMCID]

[41] de Abreu PMJE, Cruz-Santos A, Tourinho CJ, Martin R, Bialystok E. Bilingualism enriches the poor: Enhanced cognitive control in low-income minority children. Psychological Science. 2012; 23(11):1364-71. [DOI:10.1177/0956797612443836] [PMID] [PMCID]

[42] Piva Gresele AD, Garcia MV, Ortiz Torres EM, dos Santos $\mathrm{SN}$, Costa MJ. Bilingualism and auditory processing abilities: Performance of adults in dichotic listening tests. Codas. 2013; 25(6):506-12. [DOI:10.1590/S2317-17822014000100003] [PMID]

[43] Wartenburger I, Heekeren HR, Abutalebi J, Cappa SF, Villringer A, Perani D. Early setting of grammatical processing in the bilingual brain. Neuron. 2003; 37(1):159-70. [DOI:10.1016/S0896-6273(02)01150-9]

[44] Rahimi V, Mohamadkhani G, Alaghband-Rad J, Kermani FR, Nikfarjad H, Marofizade S. Modulation of temporal resolution and speech long-latency auditory-evoked potentials by transcranial direct current stimulation in children and adolescents with dyslexia. Experimental Brain Research. 2019; 237(3):873-82. [DOI:10.1007/s00221-019-05471-9] [PMID]

[45] Brandt J, Rosen JJ. Auditory phonemic perception in dyslexia-categorical identification and discrimination of stop consonants. Brain Lang. 1980; 9(2):324-37. [DOI:10.1016/0093934X(80)90152-2][PMID]

[46] Koravand A, Jutras B, Lassonde M. Abnormalities in cortical auditory responses in children with central auditory processing disorder. Neuroscience. 2017; 346:135-48. [DOI:10.1016/j. neuroscience.2017.01.011] [PMID]

[47] Russo NM, Nicol TG, Zecker SG, Hayes EA, Kraus N. Auditory training improves neural timing in the human brainstem. Behavioural Brain Research. 2005; 156(1):95-103. [DOI:10.1016/j.bbr.2004.05.012] [PMID]
[48] Pelham SD, Abrams L. Cognitive advantages and disadvantages in early and late bilinguals. Journal of Experimental Psychology. Learning, Memory, and Cognition. 2014; 40(2):313-25. [DOI:10.1037/a0035224] [PMID]

[49] Alfredo A. [Advantages and disadvantages of bilingualism (Spanish)]. Forma y Función. 2012; 25(2):99114. http:// www.scielo.org.co/scielo.php?pid=S0120338X2012000200005\&script=sci_abstract

[50] Abutalebi J, Green DW. Neuroimaging of language contro in bilinguals: Neural adaptation and reserve. Bilingualism: Language and cognition. 2016; 19(4):689-98. [DOI:10.1017/ S1366728916000225]

[51] Alexander AL, Lee JE, Lazar M, Field AS. Diffusion tensor imaging of the brain.Neurotherapeutics. 2007; 4(3):316-29. [DOI:10.1016/j.nurt.2007.05.011] [PMID] [PMCID]

[52] Cummine J, Boliek CA, Understanding white matter integrity stability for bilinguals on language status and reading performance. Brain Structure and Function. 2013; 218(2):595601. [DOI:10.1007/s00429-012-0466-6] [PMID]

[53] Abutalebi J, Brambati SM, Annoni JM, Moro A, Cappa $\mathrm{SF}$, Perani D. The neural cost of the auditory perception of language switches: An event-related functional magnetic resonance imaging study in bilinguals. Journal of Neuroscience. 2007; 27(50):13762-9. [DOI:10.1523/JNEUROSCI.3294-07.2007] [PMID] [PMCID]

[54] Stern Y. Cognitive reserve. Neuropsychologia. 2009; 47(10):2015-28. [DOI:10.1016/j.neuropsychologia.2009.03.004] [PMID] [PMCID]

[55] Bakkour A, Morris JC, Wolk DA, Dickerson BC. The effects of aging and Alzheimer's disease on cerebral cortical anatomy: Specificity and differential relationships with cognition. Neuroimage. 2013; 76:332-44. [DOI:10.1016/j.neuroimage.2013.02.059] [PMID] [PMCID]

[56] Jawabri KH, Sharma S. Physiology, cerebral cortex functions [Internet]. 2021 [Updated 2021 May]. Available from: https://www.ncbi.nlm.nih.gov/books/NBK538496/

[57] Kenny ER, Blamire AM, Firbank MJ, O'Brien JT. Functional connectivity in cortical regions in dementia with Lewy bodies and Alzheimer's disease. Brain. 2012; 135(Pt 2):569-81. [DOI:10.1093/brain/awr327] [PMID] [PMCID]

[58] Firbank MJ, Blamire AM, Teodorczuk A, Teper E, Burton EJ, Mitra D, et al. High resolution imaging of the medial temporal lobe in Alzheimer's disease and dementia with Lewy bodies. Journal of Alzheimer's Disease. 2010; 21(4):1129-40. [DOI:10.3233/JAD-2010-100138] [PMID]

[59] Cosentino S, Stern Y. Consideration of cognitive reserve. In Ravdin LD, Katzen HL, editors. Handbook on the Neuropsychology of Aging and Dementia. New York: Springer; 2013. pp. 11-23, [DOI:10.1007/978-1-4614-3106-0_2]

[60] Stern Y. What is cognitive reserve? Theory and research application of the reserve concept.Journal of the International Neuropsychological Society. 2002; 8(3):448-60. [PMID] 
This Page Intentionally Left Blank 